\title{
St. Jude Stage
}

National Cancer Institute

\section{Source}

National Cancer Institute. St. Jude Stage. NCI Thesaurus. Code C141216.

A stage defined according to St. Jude Children's Research Hospital staging system for childhood non-Hodgkin lymphoma. 